\title{
Using Explicit Teaching of Philosophy to Promote Understanding of the Nature of Science
}

\section{A Case Study from a Chinese High School}

\author{
Xiaoming Shi ${ }^{1,2}$ (D) \\ Accepted: 20 October 2020/Published online: 9 September 2020 \\ (C) Springer Nature B.V. 2020
}

\begin{abstract}
Adopting an explicit and reflective approach to the teaching of the history and philosophy of science is useful in promoting high school students' understanding of the nature of science. Whereas the history of science is usually signposted clearly in the school science curriculum, the philosophy of science is considered to be embedded in and integral to science education. This article argues that philosophical topics also need to be explicitly signposted and discussed in the teaching of the nature of science in high schools. This study investigates an interdisciplinary course on the nature of science in a Chinese senior high school. The course involved explicit teaching of philosophy of science topics with subject knowledge in each lesson. This mixed method design of the research included a modified version of the Views on Science, Technology and Society questionnaire as reported by Aikenhead and Ryan (Science Education, 76(5):477-491, 1992) and phenomenographical analysis. Although the sample size is small, the results suggest that explicit teaching of philosophy of science topics helps students better understand both the nature of science and the relationship between science, technology and society.
\end{abstract}

\section{Introduction}

In recent decades, there has been broad agreement that teaching about the nature of science (NOS) is a crucial part of school science education (McComas 2006; Lederman 2013; Clough and Olson 2008). Lederman and Lederman (2019) define NOS as concerned with the characteristics of scientific knowledge, about how science develops, which is fundamentally different from scientific inquiry and scientific knowledge. Although there are divergent definitions of the NOS (Hodson and Wong 2017), there is some consensus on the topics and skills K-12 students should be encouraged to develop. These include tentativeness and creativity, an understanding of objectivity and subjectivity, scientific theory and law, the social and cultural embeddedness of science and skills in observation and inference (McComas and Olson 1998; Lederman and Lederman 2019).

Xiaoming Shi

Xiaoming.SHI@nottingham.edu.cn

1 School of Education and English, University of Nottingham, Ningbo, China

2 Ningbo Xiaoshi High School, Ningbo, China 
In recent years, the NOS has been reflected in the syllabuses of various countries (Olson 2018), including the "Next Generation Science Standards" in the USA (McComas and Nouri 2016), "Responsible Research and Innovation (RRI)" in the EU (Laherto et al. 2018) and the recent reform of the science curriculum in China (Yao and Guo 2018; Li et al. 2018). However, how to teach students about the NOS has always been a problematic issue. Research shows that adopting explicit and reflective pedagogical approaches is effective in teaching the history and philosophy of science (HPS) (Matthews 2017; Clough 2018). Nevertheless, how and when to teach historical and philosophical scientific knowledge in the process of teaching about the NOS remain problematic for teachers (Kötter and Hammann 2017; Höttecke and Silva 2011). More specifically, previous studies have found that the history of science (HOS) is usually relatively easily reflected in the curriculum as a background to the topics being studied, but that teaching about the philosophy of science (POS) is more difficult to incorporate (Nouri and McComas 2019; Nouri et al. 2019). Matthews (2014) believes that "philosophy is inescapable in good science; it should also suggest that philosophy is inescapable in good science education" (p. 152). However, Kampourakis (2017) identifies a lack of POS content in teacher education and in university science courses. Bialystok et al. (2019) also argue that philosophy is largely absent from the high school curriculum in North America because, although they often found it rewarding, "students and teachers alike characterized philosophy as difficult." (p. 17).

In the light of these concerns, this article explores the status of philosophy of science teaching in NOS education and reports mixed methods research into using philosophical topics to teach NOS in a high school in China.

\section{Literature Review}

Losee (1980) concludes that POS is concerned with four basic questions:

1 What characteristics distinguish scientific inquiry from other types of investigation?

2 What procedures should scientists follow in investigating nature?

3 What conditions must be satisfied for a scientific explanation to be correct?

4 What is the cognitive status of scientific laws and principles?

Ladyman (2012), writing more recently, regards POS as epistemology and metaphysics. On the one hand, this definition of philosophy might prevent students and teachers without a philosophical foundation from further studying POS because it seems so abstract; on the other hand, this definition precisely reflects the importance of POS, because it supports students in recognizing the essence of science, including scientific knowledge, nature of science and the link between science and society. This is important social, as well as scientific, learning but it is rarely mentioned in textbooks (Abd-El-Khalick et al. 2008; Stansfield 2006).

POS is of great help to science teachers in understanding science and science education (Couló 2018). Elkana (2000) argues

In whatever light we see this interaction, one thing will be admitted by all; in every age it is the philosophy of science which forms the image of science in the eyes of the masses... It is not less important that it is this philosophy which determines what is 'good science' and thus determines how it should be taught. (pp. 464-465). 
Therefore, the first task for teachers in science education is to understand the standards of "good science" and be able to teach them. An advocate for HPS over 30 years, Matthews (2014), however, argues that:

Teacher education, and specifically the discipline of science education, is not in good philosophical health. Despite all of the concerns and arguments that have long been known... competence in philosophy and more specifically HPS is rare in Schools of Education, nor is their attainment much encouraged. (p. 423)

Vaesen and Katzav (2019) point to a dearth of POS projects over the last 50 years in the USA. An important element in the problem seems to be that no strong connections are being made between POS and HOS, and this lack of connection has led to a lack of professional support from philosophy in HPS teaching (Kinzel 2015). This means that, although as Matthews (2014) argues "science teachers do not have to "bring philosophy into the classroom from outside'; it is already inside" (p. 154), the reality is that most of the HPS material that already exists for teachers and educators lacks the necessary rigour and clarity, and teachers cannot use this content for effective teaching of philosophy (Ladyman 2012).

Research with undergraduates and graduates by Abd-El-Khalick (2005) indicated that students had a more in-depth understanding of NOS after they had taken a POS course. In a large-scale research study, Bialystok et al. (2019) concluded a public education curriculum in North America, which include philosophy of science, social and political philosophy, and aesthetics was considered "mindopening, yet challenging, providing educational opportunities that are largely absent in conventional schooling" (p. 1). They also found that philosophy has a connection with other disciplines. However, Bialystok, Norris and Pinto also (2019) identified problems in teachers' understanding of philosophy, particularly in middle school teaching. There is clear evidence, therefore, of problems in teacher knowledge and confidence in teaching POS in school, and a resultant lack of attention to POS in middle and high school curricula internationally. For instance, although POS is taught in Danish upper secondary education, Klausen and Brande (2016) concluded that teaching POS still faces a shortage of professional teachers and the ambiguity of teaching goals. Furthermore, Höttecke and Silva (2011) summarized the obstacles of implementing HPS in classrooms in Europe: the culture of teaching science that is different from other disciplines; teachers' skills, epistemological and didactical attitudes and beliefs about the teaching of science; the institutional framework of science teaching which is focused on curriculum development; and the lack of textbooks as fundamental didactical support. Different from POS in the western countries, Guo (2014) proposed that the philosophy of science and technology in China is derived from "Dialectics of Nature". As a political ideology providing political guidance for scientists and engineers, the audience of POS is mainly university students and researchers. Therefore, POS would not appear in Chinese high schools and cannot help Chinese students to improve their understanding of science.

Broadly, the approaches to teaching NOS through HOS or POS can be characterized as either implicit or explicit. Monk and Osborne (1997) used an implicit pedagogical method, with teachers first presenting scientific problems from the past and eliciting students' thoughts and ideas. Then, teachers combined students' conceptions with a historical study of previous scientists' ideas about the problems. Students were encouraged to consider how they might decide which version was correct by devising tests. After the introduction of the modern scientific view, students would review and evaluate the whole process through class or small group discussion. Researchers hoped that participants would understand the differences between their ideas and those of the scientists, and develop a comprehension of NOS during their own investigations of science. This implicit 
pedagogy was critiqued by Abd-El-Khalick and Lederman (2000) who said it did little to aid students' learning.

In contrast, Rudge and Howe (2009) propose an explicit and reflective pedagogical approach. The key to this approach in their course is asking questions that cause students to reflect on what they have done and what they have concluded within a scientific investigation. In each lesson, teachers would provide materials used by past scientists and questions about NOS that need to be answered at the end. The results indicate that most students improved their understanding of several aspects of NOS.

While the explicit method is positive in teaching science by prompting students to think about NOS issues, more studies have directed philosophy of science explicitly to undergraduates rather than high school students. For example, researchers successfully utilized nonscientific examples and analogies to teach lower-level courses about the philosophy of science to undergraduates and help students to be more involved in the learning materials and reduce their anxiety in learning philosophy (Slowik 2003). Considering that POS and NOS have certain epistemological similarities, then exposing high school students to philosophical topics may also improve their understanding of science.

\section{Methodology}

\subsection{Designing the Course}

In 2016, the author of this article piloted an NOS course in a high school in Ningbo, China. Considering that it is relatively rare to conduct similar courses in China, the author decided on the one hand to adopt the existing explicit and reflective approach, and on the other hand tried to increase the amount of interdisciplinary teaching on the course to help clarify the characteristics of POS. As an elective course with up to 15 participants, the basic framework of the course is $8-10$ lessons with each lesson lasting $1.5 \mathrm{~h}$. Table 1 presents the arrangement of those lessons except for the final display and exam. In the first 15-20 min of each lesson, the subject teacher introduced the relevant disciplinary knowledge, most of which was familiar to students. Next, the second teacher, the author, added topics from POS related to this knowledge. In subsequent discussions, teachers provided different reading materials or videos to motivate students to think further. These discussions also covered topics about the NOS. Therefore, this NOS course had the following characteristics:

(1) The POS topics appeared explicitly in the learning process from the outset. These topics were intended to lead students to think more about how to understand science and the connections between science and society.

(2) The POS topics were introduced through the framing of basic subject knowledge, which ensured that students could successfully enter the environment of thinking and avoid resistance to abstract philosophical topics.

(3) The POS and NOS topics were linked to promote the learning process.

Due to the constraints of length, this article introduces the arrangement of only several classes in detail and shows how the course combines the topics of philosophy and NOS. The findings from research conducted on this course are discussed below. 
To give the flavour of these lessons, this account focuses on a lesson given in the second iteration of the elective course, in 2018. Fourteen students chose this course from amongst a range of courses including Knowing China, English Film Appreciation and Chinese Piano. In the second class, a maths teacher was invited to the classroom to discuss mathematical reasoning, including deductive reasoning and inductive reasoning and to introduce students to the characteristics of inference using the math reasoning exercises that they had learned. After the maths teacher's introduction, the author provided students with other examples of deductive reasoning and inductive reasoning in life, such as Aristotle's syllogism and the phenomenon of the sun rising from the east. Then, I asked the students, "Do you think the reasoning is strict?" Most students agreed it was, based on the introduction of mathematics and common sense. Then, I showed the students two different deductive inferences:

All men are mortal. (Major premise)

Socrates is a man. (Minor premise)

Therefore, Socrates is mortal. (Conclusion)

All college entrances admitted to Tsinghua University are Chinese. (Major premise)

All of us are Chinese. (Minor premise)

We can all enter Tsinghua University. (Conclusion)The second conclusion is problematic, so I asked all students to think about the whole reasoning process. Then, the students were divided into several groups for discussion, and some students pointed out that Chinese in the major premise should be some Chinese. Furthermore, they realized that if the premise is wrong in deductive reasoning, the subsequent inference results will inevitably be biased. Students also noticed that the structure of deductive reasoning in the second example is problematic. Then, I asked the students: "Everyone says that the crow is black. If someone sees a white crow one day, what is the conclusion?" A student replied: "So we can't say that the crow is black." From this, students realized that the conclusions of inductive reasoning are not perfect, because you cannot summarize all the cases before you get the inductive result.

Next, I offered a snippet of reading material to students from Sherlock Holmes, A Study in Scarlet. The students read the story and thought about who the suspects were. I asked them: "What did you notice? Based on these observations, what can you speculate?" Finally, most students made their observations and speculations from the snippet. I compared comments

Table 1 The specific setting of the course in 2018 (including the introduction of subject knowledge, philosophical topics and NOS themes)

\begin{tabular}{|c|c|c|c|}
\hline Topics in POS & Subject introduction & Subject knowledge & NOS themes \\
\hline What is science & Psychology & The interpretation of dreams & $\begin{array}{l}\text { Social dimensions of science; } \\
\text { social and cultural } \\
\text { embeddedness of science }\end{array}$ \\
\hline Reasoning & Maths & Inductive and deductive reasoning & Inferential \\
\hline Realism & Chemistry & The structure of the atom & Empirical \\
\hline Explanation & Geography & The formation of fog & Creative; tentative \\
\hline Prediction & Physics & Quantum mechanics & Scientific theories \\
\hline Causation & Geography & The cause of haze & Empirical \\
\hline Scientific evolution & History & Changes in writing & Scientific law \\
\hline
\end{tabular}


from the students to Holmes' conclusions in the book. Students found that they could get various types of inferences from multiple observations, but that one of them is the best explanation - a view adopted by Holmes that "Inference is the Best Explanation (IBE)". Finally, I compared the observations and inferences enumerated by the students. The students realized that observations are a direct record of phenomena, and inferences are based on observations to find connections between factors.

In the third lesson, I invited a chemistry teacher to tell students about the structure of an atom. When the teacher finished the introduction, I asked students "Why is the atom like that? Do you see it? Are there tools to probe reliably?" Moreover, I put forward the issue of "realism and non-realism" from philosophy. In other words, is what we research the fact of science or just one of our descriptions? Whether what we see and observe is fact? Considering that the previous courses were conducted in the classroom, as Topçu (2013) said, "Education should move its focus from formal to emphasizing learning in both formal and non-formal settings" (p. 316). Environmental psychologists argue that educational settings can and should make education both more productive and more enjoyable. The physical setting may not make or break education on its own, but it can interact with non-environmental factors either to promote or to hinder the learning process (Gifford 2007). So, in the second part of this class, students took the relevant reading materials, and with the teacher formed a circle sitting on the lawn in the school.

In the beginning, I introduced the history of the development of ideas about realism and non-realism. At this time, some students asked whether they could lie on the grass to listen to the classes. I allowed them to lie on the lawn in any position, but said I wanted students to think. Then, we discussed topics like "Is it meaningless if it is not observable?", the "no miracle argument" that asserts that scientific realism is the best explanation and "the distinction between the observable and unobservable." On this occasion, the students responded very enthusiastically to the questions. I observed that a few girls who usually spoke very little are actively involved in the discussion. I hoped that students could look at science from different angles through this discussion and understand that the end of rationality will reach agnosticism.

In the fourth lesson, I invited a geography teacher to the lesson to discuss the question of how to explain the formation of fog. Students in the class had some prior knowledge of such a climate phenomenon. The teacher explained the reason for the three types of fog formation: cooling caused the temperature to drop below the dew point; large amounts of evaporation saturated the water vapour; full wet air and dry air were saturated. Next, I asked the students to discuss what "explaining" exactly is, based on what the teacher had just taught and using explanations in our daily life, such as a student's explanation for being late to school in the morning. I went further and asked what the meaning of "saturation" was in the teacher's explanations. I also asked what different interpretations of the same scientific phenomenon mean.

After discussion, students proposed two main conclusions:

a A good scientific explanation must be statistically related to the results to be explained.

b The key to a good explanation is to be able to unify different phenomena or provide a causal mechanism while the explanation is constantly innovating and changing.

I aimed to show students, by step by step questioning, that in fact, according to current scientific theory, science does not explain anything, and that scientific conclusions are a lot of 
laws and theory that could be overthrown at any moment. Then, I played an introductory video about the move from Newtonian mechanics to the theory of relativity. I wanted students to realize that any solid explanation can be vulnerable, and that scientific explanation is to some extent a "reasonable guess". This paved the way for the discussion of "prediction" in the next lesson.

From the above examples, we can see that the topics of POS (reasoning; realism; explanation) and the NOS (observation and inference; empirical; creativity and tentativeness) are related, so they can both be reflected in one lesson. We introduced not only the HOS (the structure of atom), but also the story (Holmes) and scientific investigation (formation of fog) in this course.

The two major research questions that underpin this work are as follows:

(1) How to effectively use POS to teach NOS?

(2) What is the impact of the teaching NOS by introducing topics from POS?

To study the impact of this course on participating students, this article uses a mixed research approach (Creswell and Clark 2017).

\subsection{Questionnaire}

Before the NOS course, we interviewed fifteen Chinese high school science teachers of physics, chemistry, biology and maths. The interview included questions about difficulties and suggestions for improving Chinese students' scientific literacy through science education. Most teachers pointed out that the existing science education curriculum and the science textbooks in China militate against students understanding science correctly. At the same time, they also believed that understanding of science, especially the concept of the relationship between science, technology and society, has a decisive role for students entering society in the future.

These concerns echoed my own views. The next stage was to seek empirical evidence of students' views of science. This was done using Views on Science, Technology and Society (VOSTS) (Aikenhead and Ryan 1992), which is a multiple-choice questionnaire initially used to evaluate Canadian students' notions of STS. Once permissions had been granted, the questionnaire was adapted to the context of Chinese students; the author selected 28 items from the questionnaire pool and invited 132 senior three (aged 16-17) Chinese students to provide their answers. The result shows 162 of all 174 original answers as proposed. Several essential options that are not mentioned in this survey are finally included in pretest and posttest questionnaires, in both of which ten questions about NOS are the same. There are 28 questions and 166 options, and only eight original options are removed in the Chinese context (Appendix 1).

All of these questionnaires have been translated into Chinese, and some words have been adjusted, such as "Canada".

All translations are done by experienced English experts to ensure the accuracy of the questionnaire. To analyse the surveys, a team of experts (the author and an expert teacher in China) assigned values to the questionnaire: realistic (2); has merit (1) and naive (0) (Appendix 2).

\subsection{Interview}

Phenomenography denotes a research approach aiming at describing the different ways a group of participants understanding a phenomenon (Marton 1986). It focuses on second-order 
description and experience of the phenomenon by different people. Marton and Pong (2005) proposed that conceptions were the units of descriptions in phenomenography:

Conception can be characterised as composed of both a referential aspect- i.e. a particular meaning of an individual object (anything delimited and attended to by subjects) - and a structural aspect- i.e. the combination of features discerned and focused upon by the subject. (p. 336)

In general, the difference between phenomenography and phenomenology is that the former focuses on the different experience of different people about the same phenomenon, while the latter concentrates on the structure and essence of the phenomenon (Cibangu and Hepworth 2016). Since the 1980s, phenomenography has been widely used in higher education research (Tight 2016). For example, Åkerlind (2005) interviewed 28 university teachers for their understanding and experience of professional growth and identified six categories of the descriptions that represent a hierarchical structure.

Phenomenography is adopted in this study because of its intent on educationally critical differences in students' ways of experiencing or understanding the subject matter (Booth \& Marton 1997). This research hopes to discover students' perceptions of the differences in science and science learning, as well as the relationship between science, technology and society.

In order to better compare the changes of these students who participated in this course, the study also added a control group, including 14 students who took other elective classes at the same time. All 28 students (both in and out of the course) were interviewed and had the questionnaires before and after the course. Bowden (2005) believe that 20 to 30 interviewees could be a decent number to create sufficient variation in the outcome space. Before and after the course, students were asked the following three questions:

(1) What is your understanding of science?

(2) How do you learn and use science in daily life?

(3) What is your conception of the relationship between science, technology and society?

Due to the limited number of participants in this study, the conclusion from questionnaire and interview is not sufficient. Mixed methods are used to collect, analyse and mix both quantitative and qualitative data in a single study to support both (Creswell and Clark 2017).

\subsection{Data Collection and Analysis}

Students were interviewed after completing the questionnaire before and after the course. Each interview lasted about $20 \mathrm{~min}$ and was conducted by the author of this article. Interview records are recorded in Chinese and were then transcribed into English.

Descriptive and inferential statistical methods were applied to the data from the questionnaire. Mean comparisons between the course group and the control group on the scale scores associated with each outcome measure were then performed to evaluate the pre-intervention equivalency of the groups. Considering the knowledge before the course, this study mainly used analysis of covariance (ANCOVA), which is used to test the effects of categorical variables on a dependent variable, while eliminating the effect of one or more interval-scaled extraneous variable. This study considers students' knowledge of science before the course and observes the changes between the groups. Before the inferential statistics, two assumptions, the dependent variable that is normally distributed and homogeneity of variance, are tested and met. 
The responses from the first interview were analysed phenomenographically to emphasize the differences in understanding of science and the relationship between science, technology and society. The primary outcome was the description of the understanding presented in hieratical scales. The researchers initially read the whole text and found the answers to the interview questions and group the related descriptions from the interview to categories. Finally, the structure of the outcome space would contain referential aspect - the different meaning of science expressed by students, and structural aspect - the logical relationship between those descriptions (Svensson 1997).

The final quantitative analysis and qualitative outcome space were then compared in this study. The sample students are identified as, for example, "A1", implying "participant 1 from the experiment group", or "B2" implying "participant 2" from the control group.

Since the entire course has nothing to do with the student's grades and graduation, the school's principal agreed to the course and study. All students participating in the course were informed in the first lesson that they could withdraw from the course or research. If students chose to leave after the first lesson, they could choose other elective courses by the regulations of the school. In this study, no students left after the first lesson. In addition, in the last class, the author gave consent forms to all the participants. If students had chosen not to use their performance and data for research, the researcher agreed to delete this part of the data.

\section{Findings}

The pre and posttest questionnaires consisted of three parts: four items on the influence of society on science/technology; five items on the influence of science/technology on society; ten items on the nature of science. The questionnaire before the intervention (Table 2) demonstrates that, before the course, there were no remarkable differences between groups regarding the nature of science and the understanding of science, technology and society: $(p>0.5)$ in $t$ test. However, the responses from both groups in the posttest questionnaire show significant differences $(p<0.5)$.

In the pretest questionnaire, the data from both groups indicates the prejudice of the students against some aspects of the NOS (Fig. 1). For example, most of them misunderstand the definitions of hypotheses, theories and their relationship (item 90511 and item 90521). Also, students had a stereotyped conception of scientific method (item 90621) and the role of error in the development of science (item 90651). However, those students in the experimental group had an improved understanding of the theory-driven nature of observation (item 90111), the tentativeness in science (item 90422) and the complexity of scientific theory (item 90541).

In Fig. 2, analysis of the same ten items about NOS after the course indicated that the values of the experimental group were higher than those of the control group (except item 90711). This result illustrates the practical improvement in the students' concepts of science from the philosophically oriented nature of science course.

In addition to NOS, the other dimensions of the research were the relationships between science, technology and society. Figure 3 shows that almost all the students in the experimental group scored significantly in both dimensions about STS after the course (except A5, A14), while the students in the control group did not change dramatically; several even scored less than before. The results of the questionnaire indicate that the NOS course with philosophical topics had a positive influence not only on understandings of the NOS but also on students' understanding of the relationship between science, technology and society. 
Table 2 Mean, standard deviation and significance between course group and control group in both questionnaires

\begin{tabular}{lllllll}
\hline Pretest & & & & Posttest & \\
& $M$ & $\mathrm{SD}$ & $t$ test & $M$ & $\mathrm{SD}$ & $t$ test \\
Course group & 17.64 & 3.48 & $(\mathrm{df}=26)$ & 30.42 & 2.98 & $(\mathrm{df}=26)$ \\
Control group & 19.36 & 3.94 & $-1.376, p>0.05$ & 22.00 & 3.59 & $6.754, p<0.05$ \\
\hline
\end{tabular}

Further analysis of the three dimensions (influence of society on science/technology; influence of science/technology on society; and nature of science) in the questionnaire found that the pretest scores on those dimensions of the experimental group were lower than those in the control group $(4.93<5.29 ; 5.36<6.29 ; 9.93<11.21)$. In the posttest, the outcome from the experimental group was higher than those of the control group (6.14> $5.00 ; 7.78>5.64 ; 16.50>11.35$ ). Through the analysis of covariance (ANCOVA), the students in the experimental group improved on the various items about the NOS (except item 90411 and item 90711 shown in Table 3). This result takes into account the comparison between the experimental group and the control group, and the students' preconceptions before the course.

The responses from the students in the interviews are related to their understanding of science, their experience of learning and applying science and their conceptions about the relationship between science, technology and society. From those responses, this research aims to dig out the whole picture of science in students' minds. The result of the first interview from the phenomenographic description is presented in five categories. The categorisation before the course represents a comprehensive understanding of science from category 1 to category 5 . The higher-level categories are logically inclusive of the previous ones in terms of the more detailed distinctions by which the understanding of the science is discerned. These classifications will be accompanied by short references to show how they relate to the data and how representative and convincing they are.

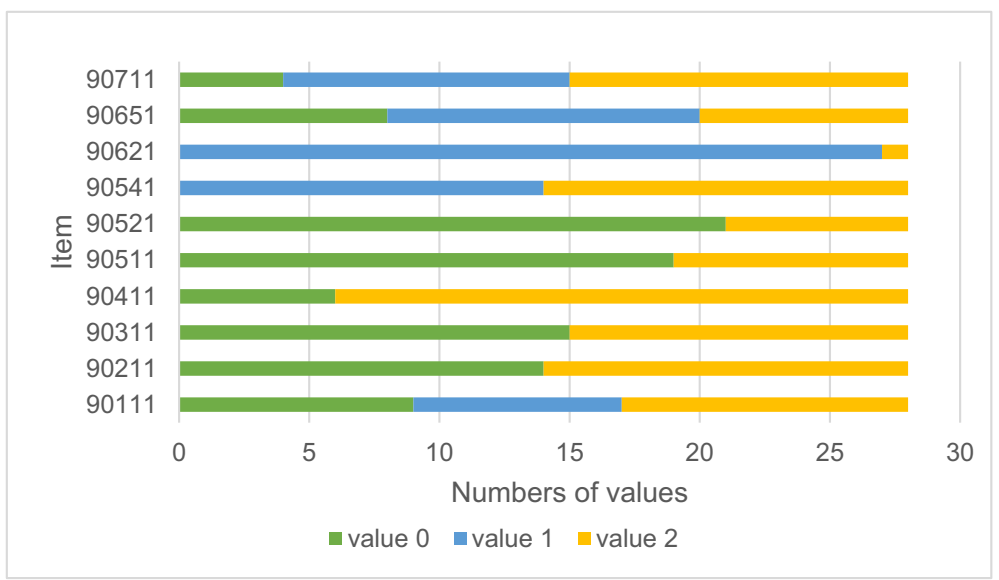

Fig. 1 The numbers of values to NOS items in pretest questionnaire $(N=28)$ 


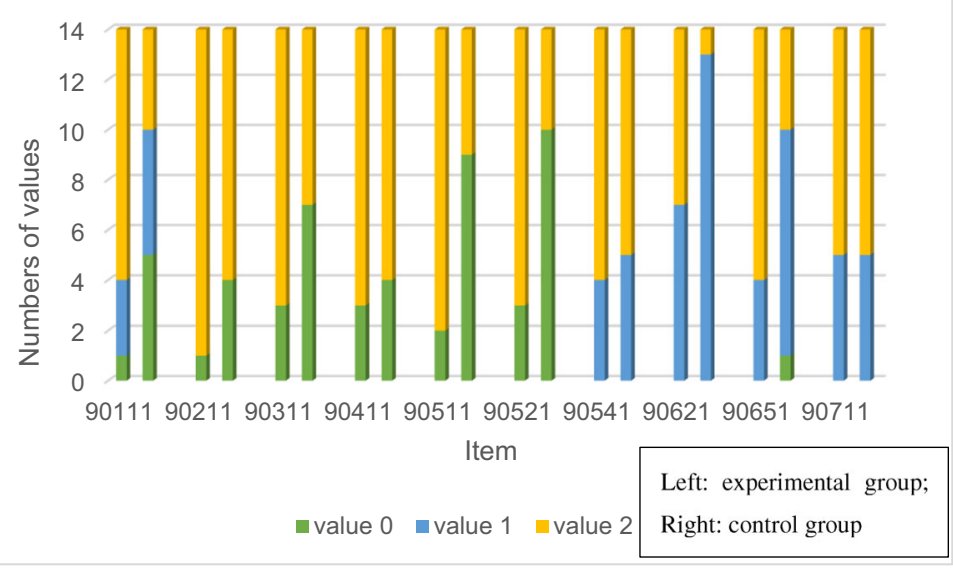

Fig. 2 The numbers of values to NOS items in the posttest questionnaire

\subsection{Descriptive Categories}

\subsubsection{Category 1: Science Is What We Learn at School}

In this category, students generally think that science consists of what is learned in school, such as physics, chemistry and biology, and they believe that this knowledge is not consistent with the situations encountered in life. For example, one student (A6) thought "Science is the content of the school textbook... You may encounter these things in life, but we do not have the opportunity to use them because the content we learned from school is different from what we encounter in life. For example, chemical experiments or physical experiments in the laboratory are completely different from those in life.".

Many students in this category believe that the primary purpose of science learning is examinations. A female student (A14) mentioned "I think learning science is tough work for

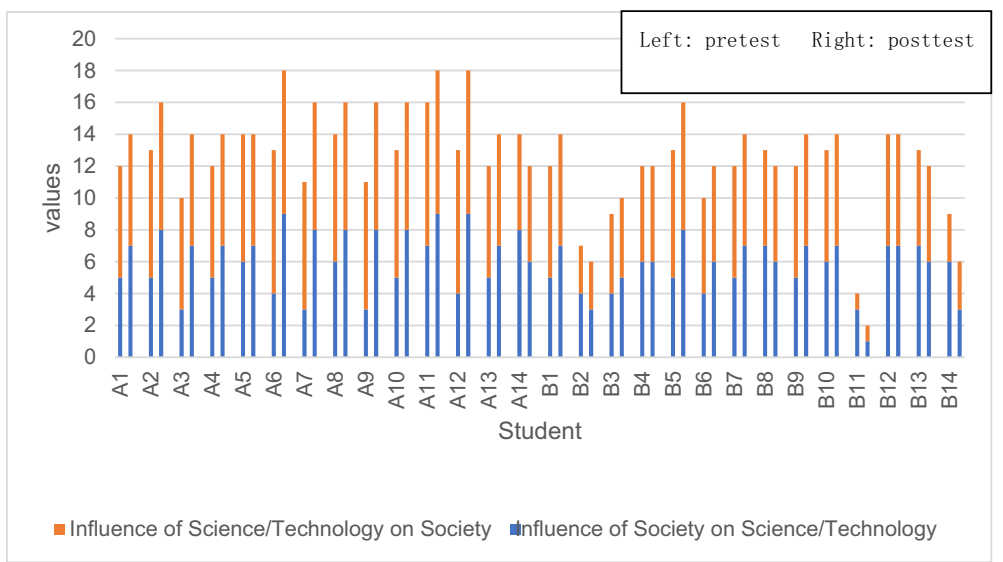

Fig. 3 The total values of influence of society on science/technology; and the influence of science/technology on society 
Table 3 Mean, standard deviation and significance between course group and control group in three dimensions and items of NOS

\begin{tabular}{|c|c|c|c|c|c|}
\hline \multirow[t]{2}{*}{ Dimensions } & \multicolumn{2}{|l|}{ Pretest } & \multicolumn{2}{|l|}{ Posttest } & \multirow[t]{2}{*}{ Sig. } \\
\hline & $\begin{array}{l}\text { Course } \\
M(\mathrm{SD})\end{array}$ & Control & $\begin{array}{l}\text { Course } \\
M(\mathrm{SD})\end{array}$ & Control & \\
\hline 1.Influence of society on science/technology & $\begin{array}{c}4.93 \\
(1.49)\end{array}$ & $\begin{array}{c}5.29 \\
(1.27)\end{array}$ & $\begin{array}{c}6.14 \\
(1.56)\end{array}$ & $\begin{array}{c}5.00 \\
(1.24)\end{array}$ & \\
\hline 2.Influence of science/technology on society & $\begin{array}{c}5.36 \\
(1.86)\end{array}$ & $\begin{array}{c}6.29 \\
(1.54)\end{array}$ & $\begin{array}{c}7.78 \\
(0.89)\end{array}$ & $\begin{array}{c}5.64 \\
(1.98)\end{array}$ & \\
\hline 3. Nature of science & $\begin{array}{c}9.93 \\
(3.05)\end{array}$ & $\begin{array}{l}11.21 \\
(2.00)\end{array}$ & $\begin{array}{l}16.50 \\
(2.47)\end{array}$ & $\begin{array}{l}11.35 \\
(2.16)\end{array}$ & 0.00 \\
\hline Item 90111 & $\begin{array}{c}1.14 \\
(0.77)\end{array}$ & $\begin{array}{c}1.00 \\
(0.96)\end{array}$ & $\begin{array}{c}1.64 \\
(0.63)\end{array}$ & $\begin{array}{c}1.00 \\
(0.87)\end{array}$ & 0.06 \\
\hline Item 90211 & $\begin{array}{c}0.57 \\
(0.91)\end{array}$ & $\begin{array}{c}1.43 \\
(0.94)\end{array}$ & $\begin{array}{c}1.85 \\
(0.93)\end{array}$ & $\begin{array}{c}1.42 \\
(0.53)\end{array}$ & 0.016 \\
\hline Item 90311 & $\begin{array}{c}0.86 \\
(1.03)\end{array}$ & $\begin{array}{c}1.00 \\
(1.04)\end{array}$ & $\begin{array}{c}1.57 \\
(0.85)\end{array}$ & $\begin{array}{c}1.00 \\
(1.04)\end{array}$ & 0.037 \\
\hline Item 90411 & $\begin{array}{c}1.28 \\
(0.99)\end{array}$ & $\begin{array}{c}1.86 \\
(0.53)\end{array}$ & $\begin{array}{c}1.57 \\
(0.85)\end{array}$ & $\begin{array}{c}1.43 \\
(0.94)\end{array}$ & 0.106 \\
\hline Item 90511 & $\begin{array}{c}0.86 \\
(1.03)\end{array}$ & $\begin{array}{c}0.43 \\
(0.85)\end{array}$ & $\begin{array}{c}1.71 \\
(0.73)\end{array}$ & $\begin{array}{c}0.71 \\
(0.99)\end{array}$ & 0.012 \\
\hline Item 90521 & $\begin{array}{c}0.57 \\
(0.94)\end{array}$ & $\begin{array}{c}0.43 \\
(0.85)\end{array}$ & $\begin{array}{c}1.57 \\
(0.85)\end{array}$ & $\begin{array}{c}0.57 \\
(0.94)\end{array}$ & 0.007 \\
\hline Item 90541 & $\begin{array}{c}1.36 \\
(0.49)\end{array}$ & $\begin{array}{c}1.64 \\
(0.49)\end{array}$ & $\begin{array}{c}1.71 \\
(0.47)\end{array}$ & $\begin{array}{c}1.64 \\
(0.50)\end{array}$ & 0.043 \\
\hline Item 90621 & $\begin{array}{c}1.07 \\
(0.27)\end{array}$ & $\begin{array}{c}1.00 \\
(0.00)\end{array}$ & $\begin{array}{c}1.50 \\
(0.52)\end{array}$ & $\begin{array}{c}1.00 \\
(0.00)\end{array}$ & 0.003 \\
\hline Item 90651 & $\begin{array}{c}1 \\
(0.96)\end{array}$ & $(0.55)$ & $\begin{array}{c}1.71 \\
(0.47)\end{array}$ & $\begin{array}{c}1.07 \\
(0.62)\end{array}$ & 0.001 \\
\hline Item 90711 & $\begin{array}{l}1 . .21 \\
(0.80)\end{array}$ & $\begin{array}{c}1.43 \\
(0.65)\end{array}$ & $\begin{array}{c}1.64 \\
(0.50)\end{array}$ & $\begin{array}{c}1.50 \\
(0.65)\end{array}$ & 0.155 \\
\hline
\end{tabular}

The numbers in italics indicate no significant difference between both groups

me because it is unlike history or politics that are closely related to our lives. I study physics in order to pass the exam." Some students mentioned that learning science relies on memory, not understanding. One student (B5) said "Physics and chemistry learning mainly depends on memory. In general, I will carefully remember those formulas, theorems, etc. before the exam, which is very helpful for the exam."

\subsubsection{Category 2: Science Is Rational Knowledge}

Responses in this category consider learning science is a process of constant thinking and analysis. They believe that science is a way to build a rational understanding of everything around them, but the purpose of rationality is still to learn more knowledge. One student (A1) mentioned that "after studying science, there have been some changes in the way I look at the world...For example, when I am about to take the exam, I will try to calm myself instead of resorting to Bodhisattva like before." Another student (A2) said, "I am better than before, I believe in science because understanding phenomena through science is often more convincing to me, at least in the course of our learning." Students in this category view science not only as a collection of knowledge but also as a process of thinking. 


\subsubsection{Category 3: Science Is the Way to Understand Nature}

Students believe that science prompts them to understand nature in a new, transcendental way. The student (A11) mentioned "I think science is to make us more objective and understand nature in detail. Many natural phenomena we encounter in life have scientific explanations behind them." Some students also mentioned that "although experience has given us much help, science is a more useful method. I am convinced that science can be applied more widely." (B4) Students believe that science is the process by which humans always discover the laws behind nature, rather than the process by which humans construct cognition themselves. As one participant (B12) summarizes "Science has made me more aware of the laws behind nature. For example, the reason for planetary motion is gravity, and the growth of green plants is due to photosynthesis."

\subsubsection{Category 4: Science Is an Artificial Construction to Understand the World}

Unlike students in category three who believe that science only helps to understand nature, students in this category further argue that science is a model built by humans for the entire world and the connections behind it. One student (A5) said "Physics makes learners begin to believe in the grandeur of the universe, recognize the great power of the environment, and begin to believe that they are just ordinary people; and biology makes me begin to question why people must die... Through genetic engineering, we may be able to overcome all diseases and ageing." This group of students also believe that science expands the horizons of learners and also gives participants more opportunities to construct their understanding of the relationship between people and science. "In the process of continuously learning science, I slowly realized that science is constantly changing... These changes are not caused by nature and the world, but we are constantly rebuilding science." (B2) These quotations emphasize that students realize the role of the human being in the process of science.

\subsubsection{Category 5: Science Is Constantly Evolving with Limitations}

In this category, learning science involves a comprehensive understanding of the world because science not only brings hope to humans but also creates problems. One girl (B13) mentioned that "when I first started studying science, I still had some doubts about science, but slowly I began to realize that scientific knowledge and methods were so successful in modern society. I thought science was omnipotent. After I was in high school, I began to pay attention to the surrounding environmental problems and found that science actually brought many problems, which seems to be difficult to deal with." This dynamic, dialectical understanding of science is different from the fixed understanding of science in previous categories.

These are hierarchical categories, which suggest that students' understandings of science range from knowledge to ability, from school to the whole world, and that they gradually begin to consider the side effects brought about by science (Table 4).

The responses from all students in the second interview, after the course, can be attributed to these same categories, but it is notable that the statements from several students have moved from one category to another category. Table 5 shows that the responses of the 13 students in the experimental group moved to more advanced positions, in category 4 and category 5. Meanwhile, almost all participants in the control group showed no change during that time. 
In both questionnaires and interviews, students who participated in the NOS course with philosophical topics enhanced their understanding of science. They viewed science not only as knowledge in school, but also as an approach to constructing understanding of the world; their responses also mentioned the close connection between science, technology and society.

\section{Discussion}

In the pretest questionnaire, most students had a basic understanding that scientists need the backbone of research, and the government can help scientists (20121). Only a few students understood the relationship between science, technology and enterprise (20211). Some students had a unilateral understanding of the influence of faith and culture on science (20411). Most of the participants before the course magnified the influence of the educational process both at home and school, although they did not deny the personal factor (20711). Some participants believed that only scientists are responsible for the development of science. Although scientists can control the content in the process, they cannot control the consequences (40121). The feedback considers the public's prejudice against science and technology but fails to notice that the government and scientists also have a prejudice against science (40211). Most of the students considered the concomitant relationship between science and technology, that is, the double-edged sword problem because it is often mentioned in school textbooks $(40311 ; 40531)$. Also, lots of students believed that science and technology would change the way of thinking (40711). Generally, students' understanding of science was mechanical and isolated, and they are unable to understand the influence of the surrounding social environment (history, culture, scientists themselves) on the development of science. This conclusion is somewhat similar to the study in Turkey (Dogan and Abd-El-Khalick 2008). For example, students in both countries "ascribed to one form or another of the naive view that the different categories of scientific knowledge (i.e., hypotheses, theories, and laws) are hierarchically interrelated in a connected progression towards achieving some higher status of 'truth' or 'correctness"' (Dogan \& Abd-El-Khalick, 2008, p. 1093). Meanwhile, most students from both countries held informed views about the tentative NOS.

In the posttest questionnaire, students on the course gradually realized the policy (20141); social organizational (20611); moral (40221) and financial (40321) influences on science. At the same time, more students in the experimental group were also aware that science could produce potential hazards (40141), such as pollution (40451). For the items about NOS, the participants in the experimental group had a more detailed and improved understanding of the

Table 4 The referential and structural aspects of the categories of ways of describing the understanding of science from the first interview

\begin{tabular}{llll}
\hline $\begin{array}{l}\text { Structural } \\
\text { aspects }\end{array}$ & Referential aspects & & \\
\cline { 2 - 4 } & Knowledge & Method & System \\
\hline Course & $\begin{array}{l}\text { 1. Science is what we } \\
\text { learn at school }\end{array}$ & & $\begin{array}{l}\text { 3. Science is the way to understand } \\
\text { nature } \\
\text { Self }\end{array}$ \\
$\begin{array}{lll}\text { 2. Science is rational } \\
\text { knowledge }\end{array}$ & $\begin{array}{l}\text { 4. Science is the artificial construction } \\
\text { to understand the world }\end{array}$ & $\begin{array}{l}\text { 5. Science is constantly } \\
\text { evolving with limitations }\end{array}$ \\
\hline
\end{tabular}


Table 5 Relations between students' responses to their understanding of science before and after the intervention

\begin{tabular}{llllllll}
\hline Initial categories of description & \multicolumn{2}{c}{ The description after the intervention } \\
\cline { 2 - 7 } & 1 & 2 & 3 & 4 & 5 & Total \\
\hline 1. Science is what we learn at school & $(2)^{1}$ & $(1)$ & 0 & 2 & 2 & $4(3)$ \\
2. Science is rational knowledge & 0 & $(3)$ & $(1)$ & 1 & 3 & $4(4)$ \\
3. Science is the way to understand nature & 0 & 0 & $(4)$ & 1 & 3 & $4(4)$ \\
4. Science is the artificial construction to understand the world & 0 & 0 & 0 & $1(2)$ & 1 & $2(2)$ \\
5. Science is constantly evolving with limitations & 0 & 0 & 0 & 0 & $(1)$ & $(1)$ \\
Total & $(2)$ & $(4)$ & $(5)$ & $5(2)$ & $9(1)$ & $14(14)$ \\
\hline
\end{tabular}

${ }^{1}$ The number in parentheses indicates the number of students in the control group

relationship between scientific models, scientific classification and reality $(90211,90311)$; the relationship between hypotheses, theory and law (90511, 90521); the scientific method (90621); and the role of error in the development of science (90651). However, there was no significant change in the control group.

The results of the questionnaire show that the students taking the course improved their understanding of the NOS and relationship between science, technology and society. The interviews also support this finding. Lots of students in the experimental group changed their answers in the interview from "Science is knowledge and method" in the first interview to "Science is the cognition established by people" and "Science is constantly developing and may produce harm" after the course. In contrast, most students in the control group still believed that science was something to be learned in the classroom.

Therefore, the explicit and reflective approach adopted towards learning about the NOS at the end of each lesson was helpful in deepening understanding of the key issues, while the explicit philosophical topics provided opportunities for further reflection on both POS and NOS. Using the development of atomic theory, Matthews (2014) argued that "philosophical considerations can contribute to its better understanding and, subsequently, to students' enriched understanding of the nature of science." (p. 338). While the HOS appears to some extent in textbooks and therefore in the classroom, how to present the philosophy of science and the nature of science in high school classrooms has remained a matter of uncertainty. The results of this study illustrate an effective approach to teaching POS in high school science education, that is, explicitly using philosophical topics, adopting existing subject content and simultaneously teaching philosophy of science and the nature of science.

High school science education should not shy away from the topics of POS but needs to think about merging the teaching of philosophy with the teaching of science. Every scientific research process is inseparable from the philosophy of science (Okasha 2016). How do scientists observe experimental results during the research process? How do scientists explain what they observed? How do scientists make predictions based on existing knowledge? Science education cannot omit these topics and only introduce conclusions. Duschl and Grandy (2013) proposes "the fundamental aspects of 'doing science' are using evidence to build theories, models, and mechanisms that explain natural systems, and to use those theories and models to devise experiments or observational studies that provide evidence" (p. 22). Thus, students need to learn explicitly how to analyse, interpret and predict; this is the scientific literacy they need to use as adult members of society. McDonald and Abd-ElKhalick (2017) point out that textbooks around the world rarely include definitions of "observation", "explanation", "prediction" or definitions of NOS. Teachers often assume that 
students understand these concepts, while teachers themselves also believe that they have understood these "obvious" concepts. For example, the items 90511 and 90521 of the first questionnaire show most students in this research did not understand the exact meaning of theory, laws and assumption. At the same time, the observed phenomena, explanations and predictions in textbooks are often presented simplistically, without discussion. However, when students leave school, they will find that the observations from different people are varied, and the interpretation of different results may be changed. Researchers can also obtain different prediction results based on the same theory. These are not questions with correct or wrong answers, but part of science itself. For example, with the recent appearance of COVID-19, scientists have many opinions about its origin and transmission route (Lipsitch et al. 2020). Scientists will come to conclusions based on different models and different research methods. Non-scientists may question science and scientists about these uncertain, changing conclusions and believe that science is not rigorous enough. This lack of understanding about the uncertainties and processes of science can give rise to belief in the certainties of pseudoscience, which is prevailing around us (Matthews 2018). The findings from our second questionnaire revealed that students in the experimental group drew clear distinctions between assumptions, laws and theory (in items 90511 and 90521). When students can explicitly understand the nature of assumption, theory and the process of science, they can better understand and use science; for example, they can appreciate scientists' predictions from models or theory better and then make their own judgement.

The focus of the POS education in high school has shifted to what and how to teach. In the course discussed above, the use of previous course knowledge to introduce the POS made it easier for students to enter the discussion of different topics. Although these philosophical topics are abstract, with the help of cases, students quickly understood the value of investigating the topics. Subject-based content can also help teachers further understand philosophical views and improve teachers' philosophical knowledge quickly. Interdisciplinary teaching also allows teachers to learn and share philosophical topics without greatly increasing workload. During this research, a chemistry teacher was invited to participate in the course and introduce atomic theory. While preparing this NOS course, she admitted that "when I was teaching the atomic theory before, I did not realize whether the structure of atoms really existed. I think I was teaching the truth... Participating in this course, I seriously considered what the atomic theory I introduced was... Although I still will not introduce these philosophical views in class, I will pay attention to the words and pedagogy during the introduction of atomic theory." After this elective course, she added, "I think it is necessary for students to think about whether the atomic structure we are learning is what we have seen, or whether it is measured by instruments, so that students can understand whether the measured structure really exists, or it is just speculation.” Matthews' account of the development of atomic theory might illustrate the importance of the transformation of teachers:

\footnotetext{
Atomic theory is a wonderful exemplar of the 2,500-year dispute between realist and instrumentalist/ empiricist/constructivist interpretations of the aims of science and of the interpretation of scientific theory. Modern atomic theory straddles many scientific domains and disciplines; it inexorably connects science with philosophy... (Matthews, 2014, p. 338)
}

In our view, teaching POS for high school students does not need to be sophisticated andindeed, cannot be - comprehensive. The six topics in this course - reasoning; realism; explanation; prediction; causation and scientific evolution - not only are closely related to life but 
also cover a large number of cases in high school science education. In the second interview, most of the students participating in the course realized that science is an artificial construction (the "Category 4: Science Is an Artificial Construction to Understand the World" section), which also indicates that the students had further considered and understood the philosophical topics explicitly raised in the courses such as realism, the explanation and prediction. Therefore, this study shows that teaching basic topics from the POS with the help of existing science content taught previously is suitable for high school students and produces positive results.

A final point is that teaching the POS and the NOS mostly overlapped in this research. Matthews (2014) proposed that learning POS "is part of learning about the nature of science, a topic in all science curricula" (p. 194). Although the definitions of the POS and the NOS are different, both of them focus on how to recognize science and the characteristics of scientific development. This makes it possible to teach the NOS using the topics of POS explicitly and reflectively. In the course we devised, topics in POS and themes in NOS are connected: for example, reasoning and the inferential in lesson two; realism and the empirical in lesson three; explanation and the creative and tentative in lesson four; prediction and scientific theories in lesson five. In other words, teaching POS and the NOS is a holistic process, not an accumulation of independent modules. As the students in the course group chose more mature views on the NOS items in their responses to the questionnaire, they also put forward more philosophical views in the second interview. One student (A9) mentioned in the second interview that "Now I am confused about these scientific knowledges, the models built by scientists and the predictions made are not certain, and they may not even exist... The charm of science, however, is we try to understand this world, whether it really exists or not." Such a reply shows that while these students are studying NOS topics like models and subjectivity, they begin to consider topics in the philosophy of science, such as realism and the nature of prediction. Due to these overlaps, discussion about philosophical topics has a positive impact on students' understanding of NOS.

\section{Conclusion}

This study introduces explicitly identified and taught topics from the POS to educate students about the NOS. Research using questionnaires and interviews shows that this method can effectively improve students' understanding of science and the relationship between science, technology and society. POS and NOS complement each other in the field of science education in high school when consistent teaching goals are set. Also, introducing topics about the POS through existing subject knowledge is demonstrated to be a feasible teaching method in this research.

However, the study raises further issues. This empirical study still lacks systematic theoretical research on the commonality of the POS and NOS. When the POS is separated from HPS, how to effectively set up courses related to the NOS in high school will be a question worth exploring. The next question is how to deal with the relationship between the POS and the HOS. In this course, we still use the HOS as a background for students to understand science in some lessons. Because it is essential to good science education, it is necessary to clarify the relationship between the HOS and POS within HPS.

The last thing to pay attention to is the audience for the philosophical topics in this NOS course. The participants in this study are high school students with strong academic ability. Moreover, this was an elective course, which these students chose by themselves. In other 
words, the characteristics of these students may have influenced the research conclusions to a certain extent. Therefore, this research result with a small sample $(N=28)$ may be limited in generalization. Subsequent research might investigate a larger, more representative sample. Nevertheless, this pedagogical approach seems to have merit.

Code Availability Software application or custom code.

Data Availability Data transparency.

\section{Compliance with Ethical Standards}

Conflict of Interest The author declares no conflict of interest.

\section{Appendix 1}

\begin{tabular}{|c|c|c|}
\hline Pretest items & Themes & Options \\
\hline 20121 & Government influence on scientists conducting scientific research & $7 / 7$ \\
\hline 20211 & The impact of business on scientific research & $5 / 6$ \\
\hline 20411 & The influence of religion and ethics on scientific research & $6 / 7$ \\
\hline 20711 & The impact of education on scientific research & $6 / 7$ \\
\hline 40121 & Scientists' responsibility for scientific research & $7 / 8$ \\
\hline 40211 & $\begin{array}{l}\text { The decision of scientists, engineers, government and the public on the use of } \\
\text { science and technology }\end{array}$ & $7 / 7$ \\
\hline 40311 & The positive and negative effects of science and technology & $8 / 8$ \\
\hline 40531 & The impact of new technologies on people's life & $6 / 6$ \\
\hline 40711 & The influence of science and technology on the way of thinking & $6 / 6$ \\
\hline Posttest items & Themes & Options \\
\hline 20141 & The impact of policy on scientists & $8 / 10$ \\
\hline 20321 & The attitude of scientists and technologists towards military research & $5 / 5$ \\
\hline 20521 & The outcome of the public in understanding science and technology & $5 / 5$ \\
\hline 20611 & The impact of social organization on scientific research & $7 / 8$ \\
\hline 40141 & Engineer's attitudes towards possible harm of the product & $7 / 7$ \\
\hline 40221 & The impact of science and technology on morality & $5 / 6$ \\
\hline 40321 & Funding in science and technology compared with public welfare & $5 / 5$ \\
\hline 40451 & Science and technology's ability to control pollution & $6 / 6$ \\
\hline 40521 & The impact of technology on job opportunities & $5 / 6$ \\
\hline $\begin{array}{l}\text { Nature of science } \\
\text { items }\end{array}$ & Themes & Options \\
\hline 90111 & The theory-driven nature of observations & $5 / 5$ \\
\hline 90211 & Relationship between scientific models and reality & $6 / 7$ \\
\hline 90311 & Relationship between classification schemes and reality & $6 / 6$ \\
\hline 90411 & Tentative nature of scientific knowledge & $4 / 4$ \\
\hline 90511 & Relationships between hypotheses, theories and laws & $4 / 5$ \\
\hline 90521 & Assumptions underlying theories and laws & $6 / 6$ \\
\hline 90541 & Nature of scientific theories (simple vs. complex) & $6 / 6$ \\
\hline 90621 & Rejection of step-wise procedures - myth of the "scientific method" & $4 / 5$ \\
\hline 90651 & Nonlinearity of scientific investigations - the role of error & $5 / 5$ \\
\hline 90711 & Precision and uncertainty in scientific knowledge - probabilistic reasoning & $5 / 5$ \\
\hline
\end{tabular}

For example, in item 20211, 5/6 means that 5 of the 6 options in the original questionnaire were mentioned by the students in this survey. 


\section{Appendix 2}

\section{Categorisation of Responses to the VOSTS Items}

Each VOSTS response in both questionnaires was categorized as representing a "naive" position $(\mathrm{N})$, a "have merit" position (HM) or a position that is "realistic" (R).

According to Dogan and Abd-El-Khalick (2008), three responses (I do not understand; I do not know enough about this subject to make a choice; None of these choices fits my basic viewpoint) are replaced with "None of the above choices fits my basic viewpoint. My basic viewpoint is (please explain your viewpoint in the space provided below):", which is not shown at the end of each item below.

\section{Pretest Questionnaire}

20121 Community or government agencies should tell scientists what to investigate; otherwise, scientists will investigate what is of interest only to them.

Your position, basically:

Community or government agencies should tell scientists what to investigate:

A (N) so that the scientists' work can help improve society.

B (HM) only for important public problems; otherwise, scientists should decide what to investigate.

C (HM) All parties should have an equal say. Government agencies and scientists together should decide what needs to be studied, even though scientists are usually informed about society's needs.

D (R) Scientists should mostly decide what to investigate, because they know what needs to be studied. Community or government agencies usually know little about science; their advice, however, might sometimes be helpful.

E (HM) Scientists should mostly decide because they know best: which areas are ready for a break-through, which areas have the experts available, which areas have the available technology and which areas have the greatest chance of helping society.

F (N) Scientists should decide what to investigate, because they alone know what needs to be studied. Governments often put their own interests ahead of society's needs.

G (N) Scientists should be free to decide what to investigate, because they must be interested in their work in order to be creative and successful.

20211 Scientific research would be better off if the research were more closely controlled by corporations (for example, companies in high-technology, communications, pharmaceuticals, forestry, mining, manufacturing).

Your position, basically:

Corporations should mainly control science:

A (N) because closer control by corporations would make science more useful and cause discoveries to be made more quickly through faster communication, better funding and more competition.

B (N) in order to improve the cooperation between science and technology, and thus solve problems together. 
C (HM) but the public or government agencies should have a say in what science tries to achieve.

Corporations should not control science:

D. (HM) because if corporations did, scientific discoveries would be restricted to those discoveries that benefit the corporation (for example, making a profit). Important scientific discoveries that benefit the public are made by unrestricted pure science.

1 (R) because if corporations did, corporations would obstruct scientists from investigating important problems which the companies wanted kept quiet; for example, pollution by the corporation.

20411 Some cultures have a particular viewpoint on nature and man. Scientists and scientific research are affected by the religious or ethical views of the culture where the work is done.

Your position, basically:

Religious or ethical views DO influence scientific research:

A (N) because scientists may unconsciously choose research that would support their culture's views.

B (HM) because most scientists will not do research which goes against their upbringing or their beliefs.

C (R) because everyone is different in the way they react to their culture. It is these individual differences in scientists that influence the type of research done.

D (HM) because powerful groups representing certain religious, political or cultural beliefs will support certain research projects, or will give money to prevent certain research from occurring.

Religious or ethical views do NOT influence scientific research:

E. (HM) because research continues in spite of clashes between scientists and certain religious or cultural groups (for example, clashes over evolution and creation).

1 (R) because scientists will research topics which are of importance to science and scientists, regardless of cultural or ethical views.

20711 Some communities produce more scientists than other communities. This happens as a result of the upbringing which children receive from their family, schools and community.

Your position, basically:

Upbringing is mostly responsible:

A (HM) because some communities place greater emphasis on science than other communities.

B (HM) because some families encourage children to question and wonder. Families teach values that stick with you for the rest of your life.

C (HM) because some teachers or schools offer better science courses or encourage students to learn more than other teachers or schools.

D (HM) because the family, schools and community all give children with an ability in science the encouragement and opportunity to become scientists. 
E (R) It is difficult to tell. Upbringing has a definite effect, but so does the individual (for example, intelligence, ability and a natural interest in science). It is about half and half.

Intelligence, ability and a natural interest in science are mostly responsible:

F. (N) because people are born with these traits.

40121 Scientists should be held responsible for the harm that might result from their discoveries.

Your position, basically:

A (N) Scientists should be held responsible because it is part of a scientist's job to ensure that no harm comes from a discovery. Science should cause no harm.

B (N) Scientists should be held responsible because, if a discovery can be used for both good and bad purposes, the scientists must promote the good use and stop the bad use.

C (HM) Scientists should be held responsible because they must be aware of the effects of their experiments ahead of time. Science should cause more good than harm.

D (R) The responsibility should be shared about equally between the scientists and society.

Scientists should NOT be held responsible:

E. (N) because it is the people who use the discoveries who are responsible. Scientists may be concerned, but they have no control over how others use their discovery.

1 (N) because the results of scientific work cannot be foreseen (we cannot predict if the results will be harmful or not). It is a chance we have to take.

2 (HM) because otherwise scientists would quit doing research and science would not progress.

3 (N) because once a discovery is made, others should check its effects. The scientist's job is only to make the discoveries. Science and moral questions are separate.

40211 Scientists and engineers should be the ones to decide what types of energy we will use in the future (for example, nuclear, hydro, solar or coal burning) because scientists and engineers are the people who know the facts best.

Your position, basically:

Scientists and engineers should decide:

A (N) because they have the training and facts which give them a better understanding of the issue.

B (N) because they have the knowledge and can make better decisions than government bureaucrats or private companies, both of whom have vested interests.

C (HM) because they have the training and facts which give them a better understanding; BUT the public should be involved - either informed or consulted.

D (R) The decision should be made equally; viewpoints of scientists and engineers, other specialists and the informed public should all be considered in decisions which affect our society.

E (HM) The government should decide because the issue is basically a political one; BUT scientists and engineers should give advice. 
F (N) The public should decide because the decision affects everyone; BUT scientists and engineers should give advice.

G (HM) The public should decide because the public serves as a check on the scientists and engineers. Scientists and engineers have idealistic and narrow views on the issue and thus pay little attention to consequences.

40311 We always have to make trade-offs (compromises) between the positive and negative effects of science and technology.

Your position, basically:

There are always trade-offs between benefits and negative effects:

A (R) because every new development has at least one negative result. If we did not put up with the negative results, we would not progress to enjoy the benefits.

B (R) because scientists cannot predict the long-term effects of new developments, in spite of careful planning and testing. We have to take the chance.

C (R) because things that benefit some people will be negative for someone else. This depends on a person s viewpoint.

D (HM) because you cannot get positive results without first trying a new idea and then working out its negative effects.

E (N) but the trade-offs make no sense. (For example: Why invent labour saving devices which cause more unemployment? or Why defend a country with nuclear weapons which threaten life on earth?)

There are NOT always trade-offs between benefits and negative effects:

F. (N) because some new developments benefit us without producing negative effects.

1 (R) because negative effects can be minimized through careful planning and testing.

2 (N) because negative effects can be eliminated through careful planning and testing. Otherwise, a new development is not used.

40531 More technology will improve the standard of living for human being. Your position, basically:

A (HM) Yes, because technology has always improved the standard of living, and there is no reason for it to stop now.

B (HM) Yes, because the more we know, the better we can solve our problems and take care of ourselves.

C (HM) Yes, because technology creates jobs and prosperity. Technology helps life become easier, more efficient and more fun.

D (N) Yes, but only for those who can afford to use it. More technology will cut jobs and cause more people to fall below the poverty line.

E (R) Yes and no. More technology would make life easier, healthier and more efficient. BUT more technology would cause more pollution, unemployment and other problems. The standard of living may improve, but the quality of life may not.

F (N) No. We are irresponsible with the technology we have now; for example, our production of weapons and using up our natural resources. 
40711 Science and technology influence our everyday thinking because science and technology give us new words and ideas.

Your position, basically:

A (N) Yes, because the more you learn about science and technology, the more your vocabulary increases, and thus the more information you can apply to everyday problems.

B (N) Yes, because we use the products of science and technology (for example, computers, microwaves, health care). New products add new words to our vocabulary and change the way we think about everyday things.

C (HM) Science and technology influence our everyday thinking BUT the influence is mostly from new ideas, inventions and techniques which broaden our thinking.

Science and technology are the most powerful influences on our everyday lives, not because of words and ideas:

D. (R) but because almost everything we do, and everything around us, has in some way been researched by science and technology.

1 (R) but because science and technology have changed the way we live.

2 (N) No, because our everyday thinking is mostly influenced by non-scientific things. Science and technology influence only a few of our ideas.

90111 Scientific observations made by competent scientists will usually be different if the scientists believe different theories.

Your position, basically:

A (HM) Yes, because scientists will experiment in different ways and will notice different things.

B (R) Yes, because scientists will think differently and this will alter their observations.

C (N) Scientific observations will not differ very much even though scientists believe different theories. If the scientists are indeed competent, their observations will be similar.

D (N) No, because observations are as exact as possible. This is how science has been able to advance.

E (N) No, observations are exactly what we see and nothing more; they are the facts.

90211 Many scientific models used in research laboratories (such as the model of heat, the neuron, DNA or the atom) are copies of reality.

Your position, basically:

Scientific models ARE copies of reality:

A (N) because scientists say they are true, so they must be true.

B (N) because much scientific evidence has proven them true.

C (N) because they are true to life. Their purpose is to show us reality or teach us something about it.

D (N) Scientific models come close to being copies of reality, because they are based on scientific observations and research.

Scientific models are NOT copies of reality: 
E. (R) because they are simply helpful for learning and explaining, within their limitations.

1 (R) because they change with time and with the state of our knowledge, like theories do.

2 (N) because these models must be ideas or educated guesses, since you cannot actually see the real thing.

90311 When scientists classify something (for example, a plant according to its species, an element according to the periodic table, energy according to its source or a star according to its size), scientists are classifying nature according to the way nature really is; any other way would simply be wrong.

Your position, basically:

A (N) Classifications match the way nature really is, since scientists have proven them over many years of work.

B (N) Classifications match the way nature really is, since scientists use observable characteristics when they classify.

C (R) Scientists classify nature in the most simple and logical way, but their way is not necessarily the only way.

D (R) There are many ways to classify nature, but agreeing on one universal system allows scientists to avoid confusion in their work.

E (R) There could be other correct ways to classify nature, because science is liable to change and new

Discoveries may lead to different classifications.

F. (R) Nobody knows the way nature really is. Scientists classify nature according to their perceptions or theories. Science is never exact, and nature is so diverse. Thus, scientists could correctly use more than one classification scheme.

90411 Even when scientific investigations are done correctly, the knowledge that scientists discover from those investigations may change in the future.

Your position, basically:

Scientific knowledge changes:

A (R) because new scientists disprove the theories or discoveries of old scientists. Scientists do this by using new techniques or improved instruments, by finding new factors overlooked before or by detecting errors in the original "correct" investigation.

B (R) because the old knowledge is reinterpreted in light of new discoveries. Scientific facts can change.

C (N) Scientific knowledge APPEARS to change because the interpretation or the application of the old facts can change. Correctly done experiments yield unchangeable facts.

D (N) Scientific knowledge APPEARS to change because new knowledge is added on to old knowledge; the old knowledge does not change.

90511 Scientific ideas develop from hypotheses to theories, and finally, if they are good enough, to being scientific laws.

Your position, basically:

Hypotheses can lead to theories which can lead to laws: 
A (N) because a hypothesis is tested by experiments, if it proves correct, it becomes a theory. After a theory has been proven true many times by different people and has been around for a long time, it becomes a law.

B (N) because a hypothesis is tested by experiments, if there is supporting evidence, it is a theory. After a theory has been tested many times and seems to be essentially correct, it is good enough to become a law.

C (N) because it is a logical way for scientific ideas to develop.

D (N) Theories cannot become laws because they both are different types of ideas. Theories are based on scientific ideas which are less than $100 \%$ certain, and so theories cannot be proven true. Laws, however, are based on facts only and are $100 \%$ sure.

E (R) Theories cannot become laws because they both are different types of ideas. Laws describe things in general. Theories explain these laws. However, with supporting evidence, hypotheses may become theories (explanations) or laws (descriptions).

90521 When developing new theories or laws, scientists need to make certain assumptions about nature (for example, matter is made up of atoms). These assumptions must be true in order for science to progress properly.

Your position, basically:

Assumptions MUST be true in order for science to progress:

A (N) because correct assumptions are needed for correct theories and laws. Otherwise, scientists would waste a lot of time and effort using wrong theories and laws.

B (N) otherwise society would have serious problems, such as inadequate technology and dangerous chemicals.

C (N) because scientists do research to prove their assumptions true before going on with their work.

D (N) It depends. Sometimes science needs true assumptions in order to progress. But sometimes history has shown that great discoveries have been made by disproving a theory and learning from its false assumptions.

E (R) It does not matter. Scientists have to make assumptions, true or not, in order to get started on a project. History has shown that great discoveries have been made by disproving a theory and learning from its false assumptions.

F (N) Scientists do not make assumptions. They research an idea to find out if the idea is true. They do not assume it is true.

90541 Good scientific theories explain observations well. But good theories are also simple rather than complex.

Your position, basically:

A (N) Good theories are simple. The best language to use in science is simple, short, direct language.

B (N) It depends on how deeply you want to get into the explanation. A good theory can explain something either in a simple way or in a complex way.

C (R) It depends on the theory. Some good theories are simple, and some are complex.

D (N) Good theories can be complex, but they must be able to be translated into simple language if they are going to be used. 
E (HM) Theories are usually complex. Some things cannot be simplified if a lot of details are involved.

F (HM) Most good theories are complex. If the world was simpler, theories could be simpler.

90621 The best scientists are those who follow the steps of the scientific method.

Your position, basically:

A (N) The scientific method ensures valid, clear, logical and accurate results. Thus, most scientists will follow the steps of the scientific method.

B (N) The scientific method should work well for most scientists; based on what we learned in school.

C (HM) The scientific method is useful in many instances, but it does not ensure results. Thus, the best scientists will also use originality and creativity.

D (R) The best scientists are those who use any method that might get favourable results (including the method of imagination and creativity).

E (HM) Many scientific discoveries were made by accident, and not by sticking to the scientific method.

90651 Scientists should NOT make errors in their work because these errors slow the advance of science.

Your position basically:

A (N) Errors slow the advance of science. Misleading information can lead to false conclusions. If scientists do not immediately correct the errors in their results, then science is not advancing.

B (HM) Errors slow the advance of science. New technology and equipment reduce errors by improving accuracy and so science will advance faster.

Errors CANNOT be avoided:

C. (R) so scientists reduce errors by checking each others' results until agreement is reached.

1 (R) some errors can slow the advance of science, but other errors can lead to a new discovery or breakthrough. If scientists learn from their errors and correct them, science will advance.

2 (N) Errors most often help the advance of science. Science advances by detecting and correcting the errors of the past.

90711 Even when making predictions based on accurate knowledge, scientists and engineers can tell us only what probably might happen. They cannot tell what will happen for certain.

Your position basically:

Predictions are NEVER certain:

A (R) because there is always room for error and unforeseen events which will affect a result. No one can predict the future for certain.

B (R) because accurate knowledge changes as new discoveries are made, and therefore predictions will always change. 
C (N) because a prediction is not a statement of fact. It is an educated guess.

D (HM) because scientists never have all the facts. Some data are always missing.

E (N) It depends. Predictions are certain, only as long as there is accurate knowledge and enough information.

\section{Posttest Questionnaire}

20141 A country's politics affect that country's scientists. This happens because scientists are very much a part of a country's society (that is, scientists are not isolated from their society).

Your position, basically:

Scientists ARE affected by their country's politics:

A (R) because funding for science comes mainly from governments which control the way the money is spent. Scientists sometimes have to lobby for funds.

B (R) because governments set policy for science by giving money to some research projects and not others.

C (R) because governments set policy regarding new developments and new projects, whether the government funds them or not. Government policy affects the type of projects scientists will work on.

D (HM) because governments can force scientists to work on a project which scientists feel is wrong (for example, weapon research), and therefore not allow the scientists to work on projects beneficial to society.

E (HM) because scientists are a part of society and are affected like everyone else.

F (HM) It depends on the country, and the stability or type of government it has.

NOT affected:

G. (N) Because science research and policy are different.

1 (N) Scientist is out of society. Only when they have some discoveries, scientists would be noticed by others.

20321 Few scientists and technologists would choose to work on military research and development.

Your position, basically:

Few would do research and development for the military:

A (HM) because many scientists and technologists would rather work in other areas which benefit human life and the environment.

B (N) because many scientists and technologists would not sacrifice their morals and contribute to the violence of war.

C (R) It depends on the person's values and research interests. Some scientists would find the military projects interesting and rewarding; other scientists would rather not work on projects related to war.

A number of scientists and technologists choose to work for the military: 
D. (HM) because most of the research money is in arms for technology and military-related research. The military offers large budgets, excellent equipment and more recognition for scientists.

1 (HM) because they know that our country's defence is important. We need more scientists in military research and development.

20521 The success of science and technology depends on how much support the public gives to scientists, engineers and technicians. This support depends on high school students - the future public_-learning how science and technology are used.

Your position, basically:

Yes, the more students learn about science and technology:

A (HM) the better they will keep the country running. High school students are the future.

B (N) the more students will become scientists, engineers and technicians, and so country will prosper.

C (R) the more informed the future public will be. They will be able to form better opinions and make better contributions to how science and technology are used.

D (R) the more the public will see that science and technology are important. The public will better understand the views of experts and will provide the needed support for science and technology.

E (N) No, support does not depend on students learning more about science and technology. Some high school students are not interested in science subjects.

20611 There are groups of people who feel strongly in favour of or strongly against some research field. Science and technology projects are influenced by these special interest groups (such as environmentalists, religious organizations and animal rights people).

Your position, basically:

Special interest groups do have an influence:

A (HM) because they have the power to stop some research projects and that field of science suffers.

B (R) because they influence public opinion and therefore the scientists.

C (R) because they influence government policy and governments decide whether to fund a research project or not.

D (HM) because some special interest groups give money for certain research projects. Some other special interest groups give money to prevent certain research projects.

E (N) Special interest groups try to have an influence but they do not always succeed because scientists and technologists have the final say.

Special interest groups do NOT have an influence:

F. (N) because the government decides the direction that research will take.

1 (N) because science and government decide what projects are important and they do them no matter what special interest groups say.

40141 When engineers come upon a dangerous idea or product in their work, they actually do inform the public authorities, no matter if it means losing their job or being demoted. 
Your position, basically:

Engineers do tell the authorities:

A (HM) because an engineer's job is to help the public, not harm them.

B (N) because engineers want to avoid the severe consequences if something goes wrong. If the public finds out, there could be lawsuits.

C (R) It depends on the engineer and the danger. Some engineers tell the authorities because of the dangerous possibilities. Others do not because they need their job to support a family or to become successful.

D (HM) Engineers do not, in good conscience, tell the authorities because engineers do not want to lose their jobs or frighten the public. Instead they conceal the idea or destroy the product so no one would know or get hurt.

E (N) Engineers do not tell the authorities because engineers want to keep their jobs and make money, even if the public is in danger.

F (N) It is not the engineer's responsibility. It is the company's responsibility. Engineers discuss the dangers with the company, and then the company tells the authorities.

G (HM) Nobody knows. We hear about the engineers who do tell the authorities. We do not hear about the secrets kept from the public.

40221 Science and technology can help people make some moral decisions (that is, one group of people deciding how to act towards another group of people).

Your position, basically:

Science and technology can help you make some moral decisions:

A (R) by making you more informed about people and the world around you. This background information can help you cope with the moral aspects of life.

B (R) by providing background information; but moral decisions must be made by individuals.

C (HM) because science and technology have nothing to do with moral decisions. Science and technology only discover, explain and invent things. What people do with the results is not the scientist's concern.

D (N) because moral decisions are made solely on the basis of an individual's values and beliefs.

E (N) because if moral decisions are based on scientific information, the decisions often lead to racism, by assuming that one group of people is better than another group.

40321 More money should be spent on science and technology even though this money will not be available for other things, such as social programs, education, business incentives and lower taxes.

Your position, basically:

MORE money should be spent on science and technology:

A (HM) so the country can be competitive with the rest of the world.

B (N) so people's daily lives can be improved; for example, by making things easier to do, creating new industries and jobs, helping the economy and solving health problems.

C (N) but only if the money is spent on such things as curing diseases, working on pollution or improving the food supply for the starving. 
D (R) The money should be spent in a balanced way as it is today. Science and technology are very important but they are not the only things that need money for progress.

E (N) LESS money should be spent on science and technology so more money is available for such things as social programs, education, business incentives and lower taxes.

$40451 \mathrm{We}$ have to be concerned about pollution problems which are unsolvable today. Science and technology cannot necessarily fix these problems in the future.

Your position, basically:

Science and technology can NOT fix such problems:

A (N) because science and technology are the reason that we have pollution problems in the first place. More science and technology will bring more pollution problems.

B (N) because pollution problems are so bad today and they are already beyond the ability for science and technology to fix them.

C (N) because pollution problems are becoming so bad that they may soon be beyond the ability of science and technology to fix them.

D (N) No one can predict what science and technology will be able to fix in the future.

E (R) Science and technology alone cannot fix pollution problems. It is everyone's responsibility. The public must insist that fixing these problems is a top priority.

F (HM) Science and technology can fix such problems because the success at solving problems in the past means science and technology will be successful in the future at fixing pollution problems.

40521 High-technology industries will provide most of the new jobs in the next 20 years.

Your position, basically:

A (HM) Yes. New information and rapid change are the keys to society's future.

B (HM) Yes, because new industries will produce hi-tech products. Public demand for these products will create new jobs.

C (HM) Yes. There will be many new jobs. Specially trained people will be needed to run and repair the new technology and to develop new kinds of hi-tech industries.

D (R) Yes. Specially trained people will be needed to run and repair the new technology, BUT it will replace some of today's jobs. Overall, the total number of jobs will be about the same.

E (N) No. Only a few new jobs will be created. More jobs will be lost because of mechanical or computerized hi-technology.

\section{References}

Abd-El-Khalick, F., \& Lederman, N. G. (2000). Improving science teachers' conceptions of nature of science: a critical review of the literature. International Journal of Science Education, 22(7), 665-701.

Abd-El-Khalick, F. (2005). Developing deeper understandings of nature of science: the impact of a philosophy of science course on preservice science teachers' views and instructional planning. International Journal of Science Education, 27(1), 15-42. 
Abd-El-Khalick, F., Waters, M., \& Le, A. P. (2008). Representations of nature of science in high school chemistry textbooks over the past four decades. Journal of Research in Science Teaching: The Official Journal of the National Association for Research in Science Teaching, 45(7), 835-855.

Aikenhead, G. S., \& Ryan, A. G. (1992). The development of a new instrument: 'Views on ScienceTechnology_Society' (VOSTS). Science Education, 76(5), 477-491.

Åkerlind, G. S. (2005). Academic growth and development-how do university academics experience it? Higher Education, 50(1), 1-32.

Bialystok, L., Norris, T., \& Pinto, L. E. (2019). Teaching and learning philosophy in Ontario high schools. Journal of Curriculum Studies, 51(5), 678-697.

Booth, S., \& Marton, F. (1997). Learning and awareness. Mahwah: Lawrence Earlbaum.

Bowden, J. A. (2005). Reflections on the phenomenographic team research process. Doing Developmental Phenomenography, 11.

Cibangu, S. K., \& Hepworth, M. (2016). The uses of phenomenology and phenomenography: a critical review. Library \& Information Science Research, 38(2), 148-160.

Clough, M. P. (2018). Teaching and learning about the nature of science. Berlin: Springer.

Clough, M. P., \& Olson, J. K. (2008). Teaching and assessing the nature of science: an introduction. Science \& Education, 17(2-3), 143-145.

Couló, A. C. (2018). Philosophy of science in science teacher education: meeting some of the challenges. In Teaching science with context (pp. 389-404): Springer.

Creswell, J. W., \& Clark, V. L. P. (2017). Designing and conducting mixed methods research. Thousand Oaks: Sage publications.

Dogan, N., \& Abd-El-Khalick, F. (2008). Turkish grade 10 students' and science teachers' conceptions of nature of science: a national study. Journal of Research in Science Teaching: The Official Journal of the National Association for Research in Science Teaching, 45(10), 1083-1112.

Duschl, R. A., \& Grandy, R. (2013). Two views about explicitly teaching nature of science. Science \& Education, 22(9), 2109-2139.

Elkana, Y. (2000). Science, philosophy of science and science teaching. Science Education, 9(5), 463-485.

Gifford, R. (2007). Environmental psychology: principles and practice. Colville: Optimal books.

Guo, Y. (2014). The philosophy of science and technology in China: political and ideological influences. Science \& Education, 23(9), 1835-1844.

Hodson, D., \& Wong, S. L. (2017). Going beyond the consensus view: broadening and enriching the scope of NOS-oriented curricula. Canadian Journal of Science, Mathematics, and Technology Education, 17(1), 317.

Höttecke, D., \& Silva, C. C. (2011). Why implementing history and philosophy in school science education is a challenge: an analysis of obstacles. Science \& Education, 20(3-4), 293-316.

Kampourakis, K. (2017). History and philosophy of science courses for science students. Springer.

Kinzel, K. (2015). Narrative and evidence. How can case studies from the history of science support claims in the philosophy of science? Studies in History and Philosophy of Science Part A, 49, 48-57.

Klausen, S. H., \& Brande, M. Philosophy of science in Danish upper secondary education. In Meeting in the Danish network for the philosophy of science, 2016.

Kötter, M., \& Hammann, M. (2017). Controversy as a blind spot in teaching nature of science. Science \& Education, 26(5), 451-482.

Ladyman, J. (2012). Understanding philosophy of science: Routledge

Laherto, A., Kampschulte, L., de Vocht, M., Blonder, R., Akaygun, S., \& Apotheker, J. (2018). Contextualizing the EU's "responsible research and innovation" policy in science education: a conceptual comparison with the nature of science concept and practical examples. EURASIA Journal of Mathematics, Science and Technology Education, 14(6), 2287-2300.

Lederman, N. G. (2013). Nature of science: past, present, and future. In Handbook of research on science education (pp. 845-894): Routledge.

Lederman, N. G., \& Lederman, J. S. (2019). Teaching and learning nature of scientific knowledge: is it Déjà vu all over again? Disciplinary and Interdisciplinary Science Education Research, 1(1), 6.

Li, X., Tan, Z., Shen, J., Hu, W., Chen, Y., \& Wang, J. (2018). Analysis of five junior high school physics textbooks used in China for representations of nature of science. Research in Science Education, 50, 1-12.

Lipsitch, M., Swerdlow, D. L., \& Finelli, L. (2020). Defining the epidemiology of Covid-19—studies needed. New England Journal of Medicine, 382, 1194.

Losee, J. (1980). A Historical Introduction to Philosophy of Science: Oxford University Press. Oxford

Marton, F. (1986). Phenomenography - a research approach to investigating different understandings of reality. Journal of Thought, 21, 28-49.

Marton, F., \& Pong, W. Y. (2005). On the unit of description in phenomenography. Higher Education Research and Development, 24(4), 335-348. 
Matthews, M. R. (2014). Science teaching: the contribution of history and philosophy of science. Abingdon: Routledge.

Matthews, M. R. (2017). Reconceptualizing the nature of science for science education. Abingdon: Taylor \& Francis.

Matthews, M. R. (2018). Feng Shui: educational responsibilities and opportunities. In History, philosophy and science teaching (pp. 3-41): Springer.

McComas, W. F. (2006). The nature of science in science education: rationales and strategies (Vol. 5): Springer Science \& Business Media.

McComas, W. F., \& Nouri, N. (2016). The nature of science and the next generation science standards: analysis and critique. Journal of Science Teacher Education, 27(5), 555-576.

McComas, W. F., \& Olson, J. K. (1998). The nature of science in international science education standards documents. In The nature of science in science education (pp. 41-52): Springer.

McDonald, C. V., \& Abd-El-Khalick, F. (2017). Representations of nature of science in school science textbooks. In Representations of nature of science in school science textbooks (pp. 1-19): Routledge.

Monk, M., \& Osborne, J. (1997). Placing the history and philosophy of science on the curriculum: a model for the development of pedagogy. Science Education, 81(4), 405-424.

Nouri, N., \& McComas, W. F. (2019). History of science (HOS) as a vehicle to communicate aspects of nature of science (NOS): multiple cases of HOS instructors' perspectives regarding NOS. Research in Science Education, 1-17.

Nouri, N., McComas, W. F., \& Aponte-Martinez, G. J. (2019). Instructors' rationales and strategies for teaching history of science in preservice settings. Science \& Education, 28(3-5), 367-389.

Okasha, S. (2016). Philosophy of science: very short introduction. Oxford: Oxford University Press.

Olson, J. K. (2018). The inclusion of the nature of science in nine recent international science education standards documents. Science \& Education, 27(7-8), 637-660.

Rudge, D. W., \& Howe, E. M. (2009). An explicit and reflective approach to the use of history to promote understanding of the nature of science. Science \& Education, 18(5), 561-580.

Slowik, E. (2003). Myth, music, and science: teaching the philosophy of science through the use of non-scientific examples. Science \& Education, 12(3), 289-302.

Stansfield, W. D. (2006). Textbooks: expectations vs. reality the DNA story. The American Biology Teacher, $68(8), 464-469$.

Svensson, L. (1997). Theoretical foundations of phenomenography. Higher Education Research and Development, 16(2), 159-171.

Tight, M. (2016). Phenomenography: the development and application of an innovative research design in higher education research. International Journal of Social Research Methodology, 19(3), 319-338.

Topçu, E. Ü. (2013). Learning and environmental design: softer learning spaces. International Journal of Architectural Research: ArchNet-IJAR, 7(2), 311-317.

Vaesen, K., \& Katzav, J. (2019). The National Science Foundation and philosophy of science's withdrawal from social concerns. Studies in History and Philosophy of Science Part A, 78, 73-82.

Yao, J.-X., \& Guo, Y.-Y. (2018). Core competences and scientific literacy: the recent reform of the school science curriculum in China. International Journal of Science Education, 40(15), 1913-1933.

Publisher's Note Springer Nature remains neutral with regard to jurisdictional claims in published maps and institutional affiliations. 